\title{
Synthesis, Characterization and Antimicrobial Activities of Schiff Base Complexes of Co (II) and Cu (II) Derived from Salicyldehyde and Diphenylamine
}

\author{
Uba Bala $^{1 *}$ \\ ${ }^{1}$ Desert Research Monitoring and Control Center, Yobe State University, Damaturu-Nigeria
}

DOI: $10.36348 /$ sijcms.2022.v05i01.002 | Received: 09.12.2021 | Accepted: 14.01.2022 | Published: 21.01 .2022

*Corresponding author: Uba Bala

Desert Research Monitoring and Control Center, Yobe State University, Damaturu-Nigeria

\section{Abstract}

This paper reports antibacterial and antifungal activities of Schiff base and that's of its metal (II) complexes (Co, Cu) derived from salicyldehyde and diphenylamine. The Schiff base and its metal (II) complexes were characterized using different analytical techniques like FTIR, melting point, solubility, and molar conductance, The Schiff base and its respective metals complexes were colored. The result from IR analysis revealed bands at $1614 \mathrm{~cm}^{-1}$ indicating the formation of azomethine $(\mathrm{C}=\mathrm{N})$ confirming the formation of Schiff base. The band at $664 \mathrm{~cm}^{-1}$ indicate the formation of complex which is assign toV(M-N) supporting coordination of Schiff base to respective metals. The solubility test result showed that both the Schiff base and complexes are soluble in most organic solvent and insoluble in water. Both the schiff base and complexes revealed sharp melting point and decomposition temperature. The molar conductance data of the complexes in Dimethylsulphoxide(DMSO) show low value of 9 and $10 \mathrm{Ohm}^{-1} \mathrm{~cm}^{2} \mathrm{~mol}^{-1}$ ) indicating the complexes are non-electrolytes. The entire compound was tested for their antibacterial and antifungal activities. The results indicated that the growth of the tested organism was inhibited by the compounds.

Key word: Schiff Base, Synthesis, Complexes.

Copyright () 2022 The Author(s): This is an open-access article distributed under the terms of the Creative Commons Attribution 4.0 International License (CC BY-NC 4.0) which permits unrestricted use, distribution, and reproduction in any medium for non-commercial use provided the original author and source are credited.

\section{INTRODUCTION}

Drug resistance is a well-known phenomenon that results when diseases become tolerant to pharmaceutical treatments. Although several classes of antibacterial and antifungal compounds are presently available, the resistance of microorganisms to these drugs has been constantly emerging. In order to address this serious medical problem, there is an urgent need to discover new drugs with novel mechanisms of action, higher activity and improved selectivity to address the severe challenge of multidrug resistance in treating bacterial infections and fungal infections. In view of this, Schiff bases and their metal complexes are attractive candidates for consideration due to their broad biological application (kasabe et al., 2010).

\section{MATERIALS AND METHODS}

All reagents and solvents used for this research were of analytical grade and were purchased from sigma Aldrich and Merck and were used without further purification the melting point was recorded on hot stage gallenkamp melting point apparatus. The infrared spectra was recorded using agilent carry 630 FTIR spectrometer in the frequency range of $400-4000 \mathrm{~cm}^{-1}$. The magnetic susceptibility was obtained at room temperature using magnetic susceptibility balance MK1 Sherwood. Conductivity measurement was carried out using Jan way conductivity meter 401 .

\section{METHODS SYNTHESIS OF SCHIFF BASE}

Exactly $0.05 \mathrm{~mol}(6.106 \mathrm{~g})$ of salicylaldehyde was mixed with $0.05 \mathrm{~mol}(8.46 \mathrm{~g})$ of diphenylamine in $25 \mathrm{~cm}^{3}$ of ethanol. The resulted mixture was heated under reflux for 2 hours and the solid product formed was separated by filtration, purified by recrystallization from ethanol, washed with ethanol, and then dried in desiccators over phosphorus pentaoxide $\left(\mathrm{P}_{2} \mathrm{O}_{5}\right)$ for 48hrs (Ubaet al., 2020). 


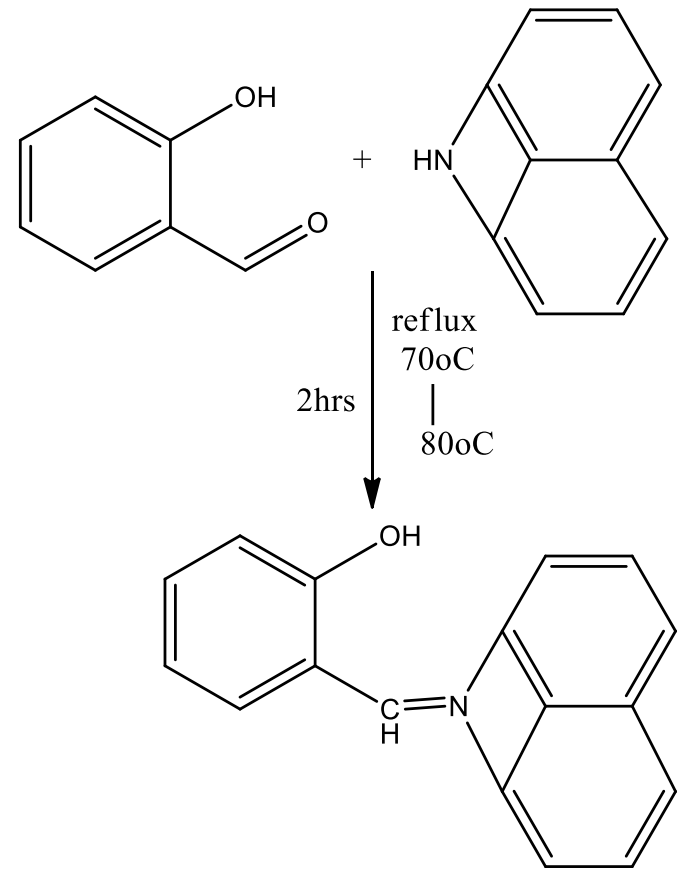

\section{SYNTHESIS OF COBALT (II) COMPLEXES}

An aqueous solution of a hydrated cobalt (II) chloride $(0.01 \mathrm{~mol}, 1.36 \mathrm{~g})$ in $10 \mathrm{~cm}^{3}$ ethanol was added to an ethanolic solution of the prepared Schiff base ligand $(0.02 \mathrm{~mol}, 2.73 \mathrm{~g})$ the mixture was refluxed for 2 hours. The precipitated complex formed was separated by filtration recrystallized and washed with ethanol and dried in a desiccator over phosphorus pentaoxide $\left(\mathrm{P}_{2} \mathrm{O}_{5}\right)$ for 48hrs (Alias et al., 2013).

\section{SYNTHESIS OF COPPER (II) COMPLEXES}

An aqueous solution of hydrated copper (II) chloride $(0.01 \mathrm{~mol}, 1.36 \mathrm{~g})$ in $10 \mathrm{~cm} 3$ of ethanol was added to an ethanolic solution of the prepared Schiff base ligand $(0.02 \mathrm{~mol}, 5.467 \mathrm{~g})$ the mixture was refluxed for 2hours. The precipitated complex formed was separated by filtrationrecrystallized and washed with ethanol and dried it in a desiccator over calcium chloride $\left(\mathrm{CaCl}_{2}\right)$ for 48 hours (Alias, et al., 2014).

\section{Media Preparation and Sensitivity test (Antibacterial and Antifungal)}

The sensitivity test was carried out by preparing sterile nutrient agar and P. D. A. media and carefully transferred into sterile petri-dishes to an appreciable amount. The media was allowed to cool and solidify at room temperature. The petri-dishes were marked to indicate fungi, bacteria and the positions of the three wells of different test concentrations (100ppm, 200ppm, 300ppm, 400ppm and 500ppm) for both the ligand and complexes. From the standardized inoculums of each isolate, uniform spreading (using a glass spreader) of $0.1 \mathrm{~mL}$ of bacteria and fungi(s) inoculums was done on the surface of dried nutrient agar and P.D. A. Each fraction of metals (II) complexes and Schiff base (ligand) petri-dishes were placed at the marked positions. For the fungi. The petri-dishes were kept in a cool dry place for 72 hours which the plate were observed for the presence for zones of inhibition as evidence of antifungal activities, while for bacteria the petridishes were kept in an incubator for 24 hours at $37^{\circ} \mathrm{C}$. The degree of sensitivity was determined by measuring the diameter of visible zones of inhibition to the nearest millimeters with respect to each isolate and test concentration and the result was recorded (Uba et al., 2020).

\section{RESULT AND DISCUSSION}

Table-1: Physical properties and analytical data of the schiff base ligand and its metal (ii) complexes

\begin{tabular}{|l|l|l|l|l|}
\hline Ligand/complexes & Color & $\mathbf{M P}^{\mathbf{0}} \mathbf{C}$ & $\mathbf{\% Y}$ & $\mathbf{M P}^{\mathbf{0}} \mathbf{C}$ \\
\hline $\mathrm{L}$ & Light blue & 190 & 46 & 190 \\
\hline$\left[\mathrm{CuL}_{2}\right]$ & Dark green & 249 & 40 & 249 \\
\hline$\left[\mathrm{CoL}_{2}\right]$ & Brown & 290 & 33 & 290 \\
\hline
\end{tabular}

Key: $\mathrm{L}=$ ligand, $\mathrm{CuL}_{2}=$ cupper complex, $\mathrm{CoL}_{2}=$ cobalt complex, $\mathrm{Mp}^{0} \mathrm{c}=$ Melting point

$\% \mathrm{y}=$ Percentage yield 
Table-2: Molar Conductance Measurement of the Complexes in Dmso Solution

\begin{tabular}{|l|l|l|}
\hline Compound & \multicolumn{1}{|c|}{ Specific conductance } & Molar conductance \\
\hline $\mathrm{Ohm}^{-1} \mathbf{c m}^{-1}$ & $\mathbf{O h m}^{-1} \mathbf{~ c m ~} \mathbf{~ m o l}^{-1}$ & \\
\hline$[\mathrm{CuL} 2]$ & $9.83 \times 10^{-6}$ & 9.83 \\
\hline$[\mathrm{CoL} 2]$ & $11.20 \times 10^{-6}$ & 11.20 \\
\hline
\end{tabular}

Table-3: the infrared spectral data of schiff base ligand and its metal (ii) complexes

\begin{tabular}{|l|l|c|c|}
\hline Compound & $\mathbf{V}(\mathbf{O H})$ & $\mathbf{v}(\mathbf{C}=\mathbf{N}) \mathbf{~ c m}^{-1}$ & $\mathbf{v}(\mathbf{M}-\mathbf{N}) \mathbf{c m}^{-1}$ \\
\hline Ligand & $\mathbf{3 0 2 2}$ & 1577 & - \\
\hline$\left[\mathrm{CuL}_{2}\right]$ & $\mathbf{3 0 4 8}$ & 1536 & 664 \\
\hline$\left[\mathrm{CoL}_{2}\right]$ & $\mathbf{3 1 6 4}$ & 1540 & 679 \\
\hline
\end{tabular}

Table-4: Solubility of Schiff Base and Its Metal (II) Complexes

\begin{tabular}{|l|l|l|l|l|l|l|}
\hline Compound & $\begin{array}{l}\text { Water } \\
\mathbf{H}_{2} \mathbf{O}\end{array}$ & $\begin{array}{l}\text { Ethanol } \\
\mathbf{C H}_{\mathbf{3}} \mathbf{C H}_{\mathbf{2}} \mathbf{O H}\end{array}$ & $\begin{array}{l}\text { Methanol } \\
\mathbf{C H}_{\mathbf{3}} \mathbf{O H}\end{array}$ & $\begin{array}{l}\mathbf{D M S O} \\
\left(\mathbf{C H}_{3}\right)_{2} \mathbf{S O}\end{array}$ & $\begin{array}{l}\text { Chloroform } \\
\mathbf{C H C l}_{\mathbf{3}}\end{array}$ & $\begin{array}{l}\text { Acetone } \\
\mathbf{C H}_{3} \mathbf{C O C H} 3\end{array}$ \\
\hline Ligand & IS & $\mathrm{S}$ & $\mathrm{S}$ & $\mathrm{S}$ & $\mathrm{SS}$ & $\mathrm{SS}$ \\
\hline$\left[\mathrm{CuL}_{2}\right]$ & $\mathrm{IS}$ & $\mathrm{S}$ & $\mathrm{SS}$ & $\mathrm{S}$ & $\mathrm{SS}$ & $\mathrm{SS}$ \\
\hline$\left[\mathrm{CoL}_{2}\right]$ & $\mathrm{IS}$ & $\mathrm{S}$ & $\mathrm{SS}$ & $\mathrm{S}$ & $\mathrm{SS}$ & $\mathrm{SS}$ \\
\hline
\end{tabular}

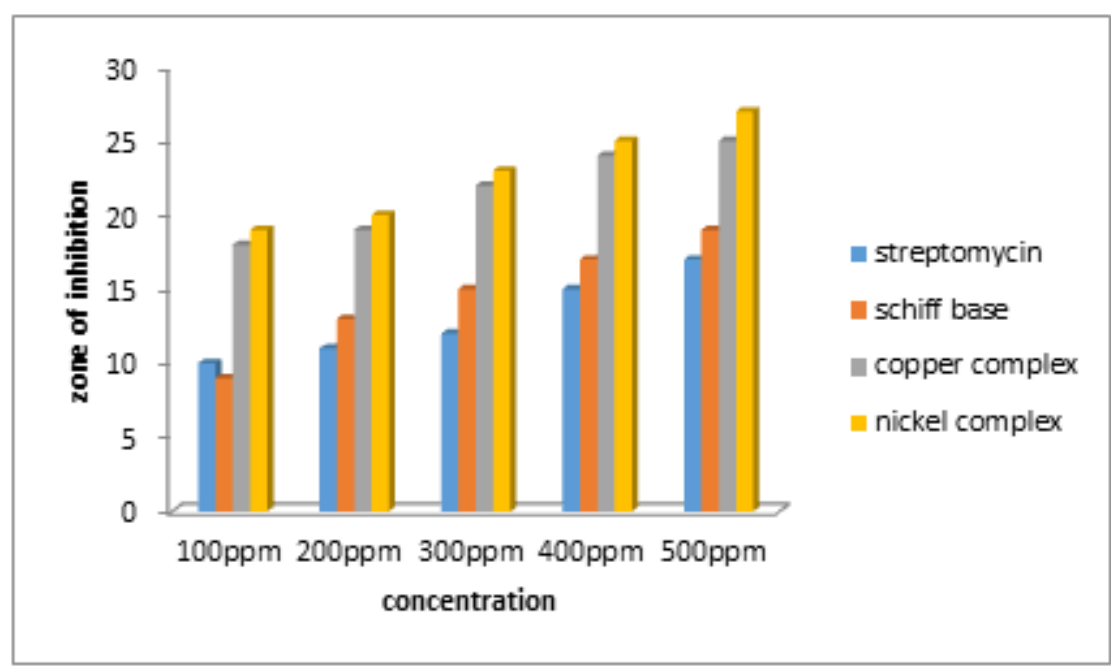

Fig-1: Sensitivity test for antibacterial activity of Schiff base and its Metal (II)

Complexes against clinical isolate (Staphylococcus aureus) using Well diffusion method

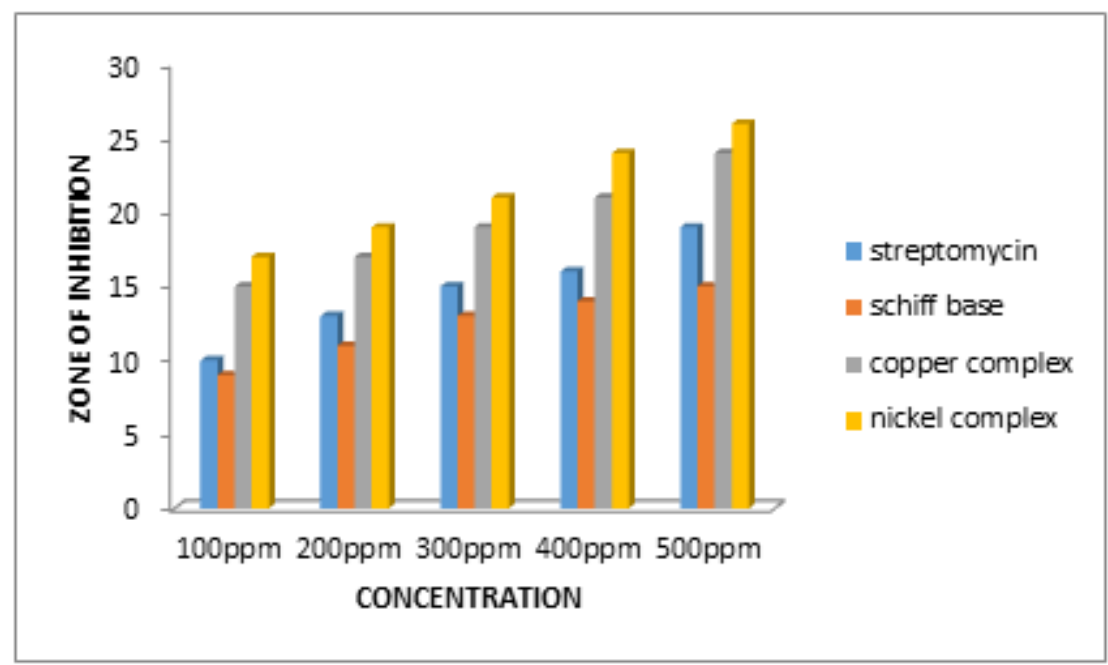

Fig-2: Sensitivity test for antibacterial activity of Schiff base and it's MetaComplexes against clinical isolate (E. coli) using Well diffusion method 


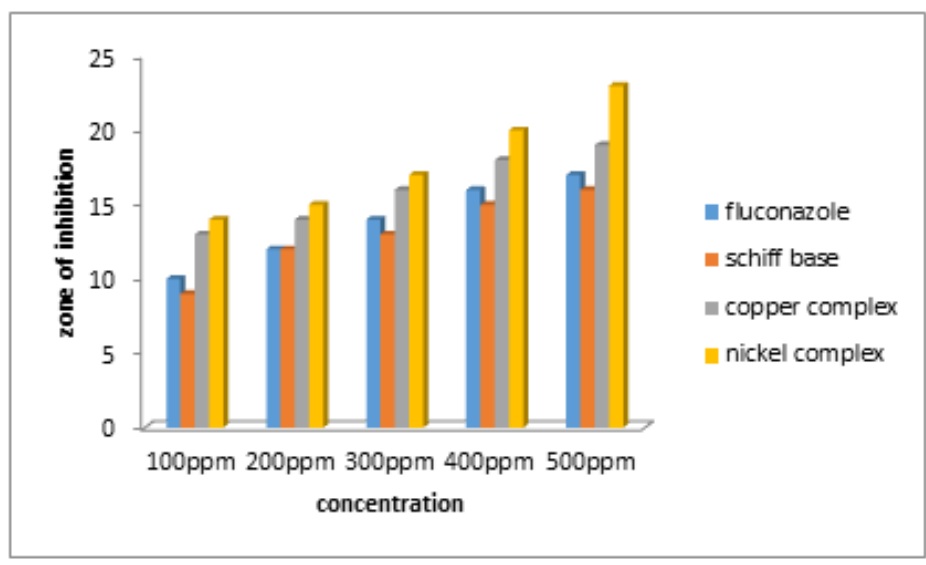

Fig-3: Sensitivity test for antifungal activity of Schiff base and its Metal (II) Complexes against clinical isolate (Aspergillus Niger) using Well diffusion method

\section{DISCUSSION}

The interaction between salicylaldehyde and Diphenylamine gives a light blue and its metal complexes of $\mathrm{Co}$ (II), and $\mathrm{Cu}$ (II) were found to be dark green and brown respectively. This is typical for transition metal complexes due to $\mathrm{d}$ - $\mathrm{d}$ electrons transition. They are non-hygroscopic solids and are air and photo stable. The purity of the Schiff base and metal complexes is established by the observance of sharp melting/decomposition temperature and for Schiff base and metal complexes were $190^{\circ} \mathrm{C}, 249^{\circ} \mathrm{C}$ and $290^{\circ} \mathrm{C}$ respectively. The percentage yield of Schiff base and complexes were 46\%, $40 \%$ and $33 \%$ respectively. As shown in Table 1.

Solubility of a compound in various solvents depends on the nature of the compound, type of bonding and solvent (satya et al., 2006). The solubility test was carried out in methanol, ethanol dimethylsulphoxide, water, chlorofoam and acetone both the Schiff base and metals complexes were found to be soluble in some solvent such as dimethylsulphoxide and ethanol. This is due to the fact that polar solvents dissolve polar compounds due to similar attractive force between them. However, they are slightly soluble in acetone and chlorofoam probable because many non-polar solvents are able to dissolve compounds containing oxygen atom, which is used in forming a bond with polar hydrogen of the carbonhydrogen in the solvent (satya et al., 2006). Both are insoluble in water. The solubility test is significance because it gives information on the best solvent that will completely dissolved synthesized Schiff base and its metal complexes to be use for antimicrobial test and other research purposes as shown in Table 4.

Electrolytic conductivity is the measure of the mobility of ions present in the solution. The ionic mobility in turn depends on the charge and size of metal ions and interaction with solvent molecules. When a metal ion forms a complex with solvent molecule or some ligands, the conductivity reduced (David et al., 1999). In this study the electrical conductivity of divalent metal ions $\left(\mathrm{M}^{2+}\right)$ in $10^{-3} \mathrm{M}$ DMSO solution was studied. It is observed that molar conductance value of Co (II), and Cu (II) Schiff base complexes determined in $10^{-3} \mathrm{M}$ DMSO solution at room temperature are (9 and $11 \mathrm{Ohm}^{-1} \mathrm{~cm}^{2} \mathrm{~mol}^{-1}$ ) their molar conductance value are low, which may be due to the fact that the metal (II) ions form a stable complexes with DMSO solution, and therefore mobility and conductance of these metal (II) complexes is lowered (David et al., 1999). And behave as non-electrolytes in DMSO. Which is similar to what Geary et al., (1971) reported. Thus it has been established that ionization is an important factor in the activity of synthetic drugs (lewis, 1954), as shown in the Table 2 .

The infrared spectrophotometer analysis which carried out on the Schiff base ligand and their metal (II) complexes as indicated in Table 3 . Above have shown the relative absorption band at $3022 \mathrm{~cm}^{-1}$ which attributed to $\mathrm{v}(\mathrm{OH})$ vibration frequency, the absorption band also shifted to different frequency of $3048 \mathrm{~cm}^{-1}$ and $3164 \mathrm{~cm}^{-1}$ for the $\mathrm{Cu}$ (II) and Co (II) of the Schiff base ligand respectively. This absorption band of such spectrum showed the coordination of the Schiff base to the respective metal (Asharaf et al., 2011). The absorption band at $1577 \mathrm{~cm}^{-1}$ could be attributed due to $\mathrm{v}(\mathrm{C}=\mathrm{N})$ i.e the azomethine group in the Schiff base ligand. Nearly this absorption band have appeared or shown in the spectra of the two complexes $1536 \mathrm{~cm}^{-1}$, $1540 \mathrm{~cm}^{-1}$ respectively, which shows a coordination of Schiff base to the respective metal (sani and Iliyasu, 2018). The strong absorption band in the same region ranging from $679 \mathrm{~cm}^{-1}$ to $664 \mathrm{~cm}^{-1}$ could be due to $\mathrm{v}$ $(\mathrm{M}-\mathrm{N})$.

Antibacterial activity of schiff base and its metal (II) complexes showed activity on Staphylococcus aureus, Escherichia coli but the activity is higher on Staphylococcus aureus compared to that of Escherichia coli with inhibitory zone of $9 \mathrm{~mm}-20 \mathrm{~mm}$ and $13 \mathrm{~mm}-23 \mathrm{~mm}$ ligand to metal complex respectively. The metal complexes on the other hand showed higher activities compared to Schiff base because of chelation 
Uba Bala., Sch Int J Chem Mater Sci, Jan, 2022; 5(1): 6-10

and $\pi$-electron delocalization, which increase the lipophilic character, favoring its permeation into the bacterial membrane, causing the death of the organisms (Agwara et al., 2010). The activities of both Schiff base and its metal (II) complexes increase as the concentration increases as shown in figure.1 and 2. The Schiff base ligand did not show much efficacy on staphylococcus aureus as compare to the metal (II) complexes, the CU (II) complex show higher activity against staphylococcus aureus at both the concentrations with inhibitory zones of 10-23 mm, followed by CO (II) complex with zones of inhibition ranging from $9-16 \mathrm{~mm}$. because of chelation and $\pi$ electron delocalization, which increase the lipophilic character, favoring its permeation into the bacterial membrane, causing the death of the organisms (Agwara et al., 2010). The Schiff base ligand show moderate activity against staphylococcus aureus but in the case of Escherichia coli, it shows modarate activity with zones of inhibition of $10-17 \mathrm{~mm}$ at both the concentrations. Co (II) complex against Escherichia Coli show higher activity at both the concentrations as well. The streptomycin which serve as the control show high activity in contrast with the Schiff base ligand. it is well known that some drugs have greater activity when administered as metal complexes than as free organic compounds (Tweedy,1964). The antifungal activity against Aspergillus niger using well diffusion method revealed that metals (II) Complexes have higher activity compared to Schiff base. The better activities of the metal complexes are attributed to the metal ions, since the metal-free ligand has low antifungal activity which is similar to that of Lawal et al., (2014).

\section{CONCLUSION}

In conclusion, the synthesis, characterization and antimicrobial activities of a Schiff base derived from salicylaldehyde and Diphenylamine and its metal (II) complexes have been described. The Schiff base ligand coordinated through its azomethine nitrogen with metal ion. This is supported by infrared spectral data. The molar conductivity data of the complexes in DMSO indicated that they are non-electrolytes. All the complexes are air stable and soluble in some of the solvents used except petroleum ether. They also form moderate yield as their percentage yield required. The in vitro antimicrobial screening of schiff base and its metal complexes showed that they are potential antimicrobial agents against the tested microorganisms.

\section{REFERENCE}

- Agwara, M. O., Ndifon, P. I., Ndosiri, N. B., Paboudam, A. G., Yufanyi, D. M., \& Mohamadou, A. (2010). Synthesis, characterization and antimicrobial activities of $\mathrm{Co}$ (II), $\mathrm{Cu}$ (II) and Zn(II) mixed - Ligand complexes containing 1,10phe nanthroline and 2, 2'- bipyridine,"Bulletin of the Chemical Society of Ethiopia, 24(3) 383-389.
- Alias, M., Huda, K., \& Carolin, S., (2014). Synthesis, physical characterization and biological evaluation of Schiff base M(II) complexes Journal of the Association of Arab Universities for Basic and Applied Sciences, 15, 28-34

- Ashraf, M. A., Mahmood, K., Wajid, A. (2011). Synthesis, characterization and biological activity of schiff bases ipcbee, 10 PP 1-7

- David T. S., Balakumar S. and suganthi, S., (1999). Effect of Complexation on the ions mobility of some 3-d metal ions. Internation journal of apply chemistry 12:38-49

- Geary, W.J., (1971). The use of conductivity measurement in organic solvent for characterization of coordination compounds, coordination Chemistry. Review, 7(1) 81- 122

- Gomathi, V., Selvameena, R. (2013). Synthesis, spectroscopic, electrochemical and biological studies of novel schiff base complexes derived from 4-(- ethoxyhydroxybenzaldeneamino)-N(pyridine-2-yl) benzensulfonamide. Main group SSchem, 12; 275-284

- Sani, U., \& Iliyasu, S.M. (2018). Synthesis, Characterization And Antimicrobial Studies On Schiff Base Derived From 2-Aminopyridine And 2-Methoxybenzaldehyde And Its Cobalt (Ii) And Nickel (Ii) Complexes Bayero Journal Of Pure And Applied Sciences, 11(1):Pp 214 - 219 Issn 2006 6996

- Kasabe, A., Mohite, V., Ghodake, J., \& Vidhate, J. (2010). Synthesis, Characterization and Primary Antimicrobial, Antifungal Activity Evaluation of Schiff bases of 4-Chloro-(3substitutedphenylimino)- methyl-[2H] - chromene2-OneE-Journal of Chemistry e-journals.net, 7(2),377-382

- Lawal, A., Obaleye, J.A., Adediji, J.F., Amolegbe S.A., Bamigboye, M.O., Yunus- Issa, Mt., (2014). Synthesis, Characterization and Antimicrobial Activities of Some Nicotinamide - metal Complexes, Journal of Applied Science and Enviromental Management, 18(2); 205-208

- Tweedy, B.G. (1964). Plant extracts with metal ions as potential antimicrobial agents. Phytopathology, 55, 910-914.

- Uba. B., Muhammad, C., Uba, A., Amali, A.M. (2020). Synthesis, characterization, Antibacterial and Antifungal Activities of Schiff Base Complexes of $\mathrm{Ni}$ (II) And $\mathrm{Cu}$ (II) derived from 2hydroxy-1-napthaldehyde and 4-aminophenol. IAR J. Pharm, 1(1) 1-5

- Lewis, G.P. (1954). The Importance of Ionization in the Activity of Sympathomimetic Amines. British Journal of Pharmacology, 9, 488.

- $\quad$ Satya, P., Tuli, G. D.,

Basu, S.K., \& Madan, R. D. (2006). Advanced Inor ganic chemistry Chand S. and Company, 33; 40-50. 